\title{
Interaction of trace metals with natural particle surfaces: Comparison between adsorption experiments and field measurements
}

\author{
Dedicated to Werner Stumm for his $65^{\text {th }}$ birthday
}

\author{
Beat Müller and Laura Sigg \\ Swiss Federal Institute of Technology Zurich (ETHZ) \\ and Federal Institute for Water Resources and Water Pollution Control (EAWAG), \\ $\mathrm{CH}-8600$ Dübendorf, Switzerland
}

Key words: Trace metals; zinc; lead; adsorption; surface complexation; field study.

\begin{abstract}
The distribution of the metal ions $\mathrm{Zn}$ and $\mathrm{Pb}$ between particulate and dissolved phase in river Glatt was studied by field measurements and compared with calculated simulations, using parameters obtained by adsorption experiments with natural suspended particulate material. Differences in distribution coefficients obtained from field data are observed in function of the sampling locations and of the composition of the particulate matter.

Experiments in which metal ion solutions are titrated with a suspension of natural particles and analyzed by anodic stripping voltammetry, are interpreted in terms of binding capacities and conditional stability constants of $\mathrm{Zn}$ and $\mathrm{Pb}$ with the surface sites. Binding constants of a particular metal ion varied very little for all samples. We obtained mean values for the conditional average complex formation constants at $\mathrm{pH} 8$ of: $\log { }^{\text {cond }} K_{\mathrm{pb}}=9.44 \pm 0.18$ and $\log { }^{\text {cond }} K_{\mathrm{Zn}}=8.17 \pm 0.20$. At this $\mathrm{pH}$, binding capacities of $5 \cdot 10^{-3}-1.7 \cdot 10^{-2} \mathrm{~mol} / \mathrm{kg}$ of particles were obtained for samples collected at different locations and times; organic material, iron and manganese oxides are considered to be the main components that control the adsorption to the particles.

Distribution coefficients are calculated from the experimentally obtained binding capacities and conditional stability constants. Calculated distribution coefficients for $\mathrm{Zn}$ agree with those obtained from the field data and are not very sensitive to changes in the composition of the solution. Good agreement was obtained for lead as well; for some samples it was important to take two types of sites with different affinity into consideration.
\end{abstract}

\section{Introduction}

The distribution of metal ions between particulate and dissolved phases is of great importance with regard to their interactions with organisms, to possible toxic effects and to their uptake, as well as with regard to their transport, to their immobilization 
in sediments and to infiltration into groundwater (Whitfield and Turner, 1987; Morel and Hudson, 1985; Jacobs et al., 1988). Information on total concentrations of trace elements in water is not sufficient in order to evaluate their ecological impact and their fate in natural water; it is necessary to gain insight into their speciation.

Binding of metals to suspended particles and to sediments is a primary process regulating their concentrations in solution. Elaborate models of the interactions of metal ions with well-defined surfaces have been established on the basis of experimental studies (Schindler and Stumm, 1987; Westall, 1987; Sposito, 1984). Oxides like iron oxides, silicate, aluminum oxides may serve as models of the naturally occurring particles and have been thoroughly studied (Schindler and Stumm, 1987). Suspended particles in natural waters consist of different inorganic particles and of organic material originating from living or decomposing organisms; algae and bacteria act upon the speciation of metal ions by binding to their surfaces and by uptake into the cells. There are indications of the importance of biological material in scavenging metal ions in lakes (Sigg et al., 1987) and of the iron oxides in acting as adsorbing phases in various systems (Tessier et al., 1985; Johnson, 1986; Lion et al., 1982). Few attempts have been made to characterize naturally occurring particles with respect to their binding properties for metal ions (Balistrieri et al., 1981, 1983; Lion et al., 1982; Mouvet and Bourg, 1983; Johnson, 1986; Tessier et al., 1985); these various studies indicate the usefulness of the surface complexation approach. Ligands in solution further influence the distribution of metal ions; inorganic and organic ligands of biological orgin (humic and fulvic acids, exudate products of algae) as well as synthetic ligands may be present in natural waters.

The objectives of the present work are to examine the distribution of metal ions between water and particles in a small river system and its dependence on different factors. Both field measurements and laboratory experiments using natural particles are used in order to describe this distribution; the results from these two different approaches are compared. It is attempted to rationalize the field data in terms of interactions of the metal ions with the available particle surfaces and to quantitatively describe these interactions with surface complexation parameters obtained from the laboratory experiments; the role of different surfaces is evaluated. Simple equilibrium models are used in order to predict changes in the distribution as a function of different parameters.

\section{Experimental part}

River system

River Glatt is a small river originating in Greifensee, an eutrophic lake; further downstream it is strongly influenced by the inputs of several large sewage treatment plants. Results from two sampling sites will be compared, namely Fällanden $(F)$ which is about $1 \mathrm{~km}$ from the lake outlet, without further tributaries, and Rümlang (R), $14 \mathrm{~km}$ downstream, after the inputs of several sewage plants. The average water discharge is about $3 \mathrm{~m}^{3} / \mathrm{s}$ in Fällanden and $8 \mathrm{~m}^{3} / \mathrm{s}$ in Rümlang. 


\section{Sampling}

Water and particle samples were taken monthly (with some interruptions) from May 1986 to March 1988 at both sites. Water samples (30-401) were taken by hand sampling, using a clean polyethylene bucket; $500 \mathrm{ml}$ were immediately acidified to $\mathrm{pH} 2$ in order to determine the total metal concentrations. The suspended particles were isolated by centrifuging continuously $30-401$ of water; the centrifugation was carried out within a few hours of the sampling after return to the laboratory. These particles were then freeze-dried and kept for analysis and for use in laboratory experiments. $0.5-11$ of water were filtered $(0.45 \mu \mathrm{m})$; the metal concentrations in the filtrate and in the particulate matter collected on the filter were determined.

All parts coming into contact with the samples were checked for contamination; bottles and filtration device were cleaned with $0.1 \mathrm{M} \mathrm{HNO}_{3}$.

\section{Analytical methods}

Water samples were analyzed directly after acidification to $\mathrm{pH} 2$ with $\mathrm{HNO}_{3}$ and preconcentration by evaporation to about $1 / 10$ of the original volume. Centrifuged particles and particles collected on filters were digested with $\mathrm{HNO}_{3} / \mathrm{HCl}$ (aqua regia).

$\mathrm{Fe}, \mathrm{Ca}, \mathrm{Zn}$ and $\mathrm{Mn}$ were analyzed by flame atomic absorption spectrometry; $\mathrm{Pb}$ was determined by graphite furnace atomic absorption. The detection limits are about $0.1 \mathrm{nmol} / \mathrm{l} \mathrm{Pb}$ and $15 \mathrm{nmol} / 1 \mathrm{Zn}$ in the water samples, $0.05 \mu \mathrm{mol} / \mathrm{g} \mathrm{Pb}, 0.5 \mu \mathrm{mol} / \mathrm{g} \mathrm{Zn}$ and $0.5 \mu \mathrm{mol} / \mathrm{g} \mathrm{Fe}$ and $\mathrm{Mn}$ in the particle samples. Contamination problems during filtration are however encountered, especially for $\mathrm{Pb}$.

Total $\mathrm{P}$ in the particles was measured in the digested samples by the molybdate method.

Organic carbon in the particles was determined by high-temperature combustion of the dried particles and IR-spectrometry of $\mathrm{CO}_{2}$ with a Dohrmann DC 80 instrument.

\section{Laboratory experiments}

The adsorption of the metal ions $\mathrm{Pb}$ and $\mathrm{Zn}$ on the natural particle surfaces was examined; metal ions were allowed to react with a suspension of the centrifuged particles in order to determine conditional stability constants and binding capacities of the particle surfaces. Conditions were chosen to approximate natural conditions. The procedures used were tested before with goethite as well defined particles. They are described in detail together with the results obtained by Müller (1989) and Müller and Sigg (1990). A solution of the metal ions $(\mathrm{Pb}$ or $\mathrm{Zn})\left(5 \cdot 10^{-8} \mathrm{M}\right.$ or $1.5 \cdot 10^{-7} \mathrm{M}$ in $10^{-2} \mathrm{M} \mathrm{KNO}_{3} / 10^{-3} \mathrm{M} \mathrm{NaHCO}_{3}$ buffered with $\mathrm{N}_{2} / 0.06 \% \mathrm{CO}_{2}$ ) was titrated with increments of a suspension of particles $(1-30 \mathrm{mg} / \mathrm{l}$ respectively $1-60 \mathrm{mg} / 1$ in the final suspension) at constant $\mathrm{pH}(\mathrm{pH}=8.0)$. The concentrations of metal ions in solution (labile metal species) were determined by differential pulse anodic stripping voltammetry (DPASV) in presence of the particles 20-30 minutes after each addition; the concentrations of $\mathrm{Pb}$ or $\mathrm{Zn}$ bound to particles were determined by 
difference, after correcting for the losses due to adsorption on the vessel walls. The distribution of the total metal between the solution and the surfaces of the measuring cell was determined at the beginning of each experiment and was introduced as a quotient in the calculations. It was assumed to remain constant during one titration experiment. The voltammetric determination in the suspension has the advantage that it includes no separation step and measures only metal ions present as free metal ions and labile complexes. From the titration curves (metal in solution in function of suspended particles added), stability constants and binding capacities were calculated. The concentration of metal ions already contained in the particles was included in the calculations; it was checked that a significant fraction of these metal ions were labile in adsorption experiments by acidifying the suspension to $\mathrm{pH} 4$; results indicated that about $50 \%$ of total $\mathrm{Pb}$ and $\mathrm{Zn}$ in the particles desorbed at $\mathrm{pH} 4$.

A modified version of MICROQL (Westall, 1979) was used for speciation calculations. Stability constants for the complexation in solution were taken from Smith and Martell (1976).

\section{Theoretical part:}

A simple model for the interactions of metal ions with natural particles and for their distribution between particulate and dissolved forms

In a simple approximation for the interactions of metal ions with natural suspended particles we assume that the distribution between particulate and dissolved forms can be described in terms of binding of metal ions to the particle surfaces and of a competition between dissolved and surface ligands. From the composition of these particles (s. below), we may assume that the most abundant surfaces available for the binding of metal ions will be organic material, iron oxides and manganese oxides. Mineral particles, clay minerals etc. are only of minor importance, especially in the particles from the lake outlet; calcium carbonate will probably not provide sufficiently large surfaces (Sigg, 1987). While the surfaces of iron and manganese oxides may be thought of as rather homogeneous surfaces with a number of equivalent surface $\mathrm{OH}$-groups, the surfaces of organic material represent in itself a heterogeneous system with a number of different functional groups.

The concentration of metal ions adsorbed on particle surfaces $\left(M e_{\text {ads }}\right)$ is the sum of metal ions bound to different types of surface ligands, on one hand $\equiv \mathrm{FeOH}$, $\equiv \mathrm{MnOH}$ and other oxides and on the other hand organic surface ligands such as $-\mathrm{COOH},-\mathrm{NH}_{2},-\mathrm{ROH}$ etc. (summarized here as $\equiv L$ ):

$$
\begin{aligned}
\{M e\}_{\mathrm{ads}}=\sum\left\{(\equiv \mathrm{FeO})_{i} M e\right\} & +\sum\left\{(\equiv \mathrm{MnO})_{i} \mathrm{Me}\right\}+\sum\left\{(\equiv L)_{i} M e\right\} \\
& +\ldots[\mathrm{mol} / \mathrm{kg}]
\end{aligned}
$$

At constant $\mathrm{pH}$ the extent of binding is primarily dependent on the concentration of available surface groups and thus on the composition of the particles. The interaction of a metal ion with each of these different surface groups is characterized by a defined surface complexation constant, which is further influenced by surface charge and surface coverage. 
The total concentration in solution is the sum of the different species which include mostly carbonate and hydroxo species and complexes with natural organic ligands $\left(L_{i}\right)$. NTA and EDTA-species are added when needed.

$$
\begin{aligned}
{\left[M e_{\mathrm{sol}}\right]=} & {\left[\mathrm{Me} e^{n+}\right]+\sum\left[\mathrm{Me}(\mathrm{OH})_{n}\right]+\sum\left[\mathrm{Me}\left(\mathrm{CO}_{3}\right)_{n}\right]+\sum\left[\mathrm{Me} L_{i}\right] } \\
{\left[\mathrm{Me}_{\mathrm{sol}}\right] \quad\left[M e^{n+}\right]\left(1+\sum \beta_{\mathrm{OH}}\left[\mathrm{OH}^{-}\right]^{n}+\sum \beta_{\mathrm{CO}_{3}}\left[\mathrm{CO}_{3}^{2-}\right]^{n}\right.} & \left.+\sum \beta_{i}\left[L_{i}\right]\right)=\left[M e^{n+}\right] \cdot \alpha_{1}
\end{aligned}
$$

$\alpha_{1}$ can be calculated for a solution of known composition; in the simplest case only carbonate and hydroxo species are included.

Distribution coefficients may be theoretically represented in terms of the surface and solution species and in terms of the complexation constants both with surface ligands and with ligands in solution (Schindler, 1984):

$$
K_{d}=\frac{\left\{M e_{\text {ads }}\right\}}{r_{-}}=\frac{\sum\left\{\left(\equiv S_{i}\right)_{j} M e\right\}}{\left[M e^{n+}\right] \alpha_{1}}=\frac{\sum \beta_{i}^{s}\left\{\equiv S_{i}\right\}^{J}\left[H^{+}\right]^{-j}}{\alpha_{1}}\left[\frac{\mathrm{mol} / \mathrm{kg}}{\mathrm{mol} / \mathrm{l}}\right]
$$

where $\beta_{i}^{s}$ represents a surface complexation constant, $\left\{\equiv S_{i}\right\}$ the concentration of surface sites and $n$ the number of $\mathrm{H}^{+}$involved in the surface complexation reaction.

Distribution coefficients are often derived from field measurements of dissolved concentrations and of concentrations in the suspended matter. They represent the average of a large number of interactions which cannot be distinguished. Differences in $K_{d}$ observed in the field measurements may thus be due to differences in the particle composition (surface ligands), on one hand and in the solution composition (dissolved ligands), on the other hand. It is however difficult to distinguish between these two types of effects from the field measurements, since for example informations on the concentrations of the natural organic ligands and of NTA and EDTA are usually missing.

In laboratory experiments it is attempted to selectively examine the binding to the particle surfaces; the speciation in solution is controlled by using an ionic medium of known composition. From these experiments, conditional stability constants and binding capacities are derived as mentioned above. In spite of the heterogeneity of the material, we were able to interprete the data in terms of discrete ligands, which gives one or two conditional stability constants and binding capacities; the applicability of this approach implies that some of the surface groups are sufficiently dominant in terms of number and affinity.

Conditional stability constants of the type:

$$
\begin{array}{cc}
K_{L} & {[\equiv L M e]} \\
& {[M e][\equiv L]}
\end{array}
$$

are derived at constant $\mathrm{pH}$, together with corresponding binding capacities $\equiv L_{T}$ With:

$$
\left[M e_{T}\right]=[L M e]+\left[M e_{\text {sol }}\right]=[\equiv L M e]+\alpha_{1}\left[M e^{+n}\right] \text { constant }
$$


and

$$
\left[\equiv L_{T}\right]=[\equiv L]+[\equiv L M e]=\left\{\equiv L_{T}\right\} \cdot A
$$

where $\left\{\equiv L_{T}\right\}$ means the total concentration of surface ligands in (mol $/ \mathrm{kg}$ ) of solid material, [ $\equiv L M e$ ] the concentration of metal bound to the surface ligands $L$ expressed in (mol/l), [Me sol $]$ is the concentration of metal in solution and $A$ the concentration of suspended solids in $(\mathrm{kg} / \mathrm{l})$, one may derive the following expression (Ruzic, 1982, 1987; Van den Berg, 1979):

$$
\frac{\left[M e_{\text {sol }}\right]}{\{\equiv L M e\}}=\frac{\alpha_{1}}{K_{L}\left\{\equiv L_{T}\right\}}+\frac{\left[M e_{\text {sol }}\right]}{\left\{\equiv L_{T}\right\}}
$$
which allows the calculation of $\equiv L_{T}$ and $K_{L}$ from a linear plot of $\frac{\left[M e_{\text {sol }}\right]}{\{\equiv L M e\}}$ ver-
sus $\left[M e_{\text {sol }}\right]$.

This approach is limited to cases where one type of surface group dominates a substantial part of the experimental range and thus gives a straight line. The parameters characterize the solid material of varying composition and allow a comparison of different samples.

With these experimental surface reaction parameters and the speciation program MICROQL we calculated the species distribution in the river using metal and particle concentrations, $\mathrm{pH}$ and alkalinity measured in the river at the concerned sampling date. Various assumptions for the complexation in solution may be used, which affect $\alpha_{1}$ and thus $K_{d}$. The speciation results allowed easy calculation of the distribution coefficients $K_{d}$, according to eq. 4 .

Different metal ions compete for the surface sites of natural particles. Since we neglect all trace metals except $\mathrm{Zn}$ and $\mathrm{Pb}$ and especially $\mathrm{Ca}^{+2}$ and $\mathrm{Mg}^{+2}$ which might be able to reduce adsorption substantially, the calculated values for $K_{d}$ can only be rough estimates.

\section{Results}

The results obtained in field measurements and in laboratory experiments will be given here for few examples, which have been studied in detail. The examples chosen are representative of the results obtained for the water and particle composition on other sampling dates. The detailed results will be given elsewhere (Müller, 1989; Sigg et al., 1990).

Characteristic differences in the particle and water composition are found at the two sites considered in this study, which reflect the influence of the lake outlet in Fällanden and of the discharge from the sewage treatment plants in Rümlang, respectively.

Concentrations of lead and zinc measured in the water samples, in the filtrate and in suspended matter, are represented in Fig. $1 \mathrm{a}$ and $1 \mathrm{~b}$ for the two sampling sites. The 
concentrations of lead and zinc in the particulate matter are given in Table 1. These concentrations illustrate the differences between the two sampling sites; at the lake outlet we find very low concentrations of lead both in the water and particles and rather low concentrations of zinc in water while zinc in the particles varies due probably to seasonal variations of the particle composition. The concentrations of lead in the filtrates are at this site near the detection limit and therefore inexact. As expected for a much higher level of pollution at the second site (Rümlang), much higher concentrations both of zinc and lead are found in the water as well as in the particles.

The particulate concentrations measured in water are highly dependent on the water discharge conditions and on the concentrations of suspended matter. It is

a)
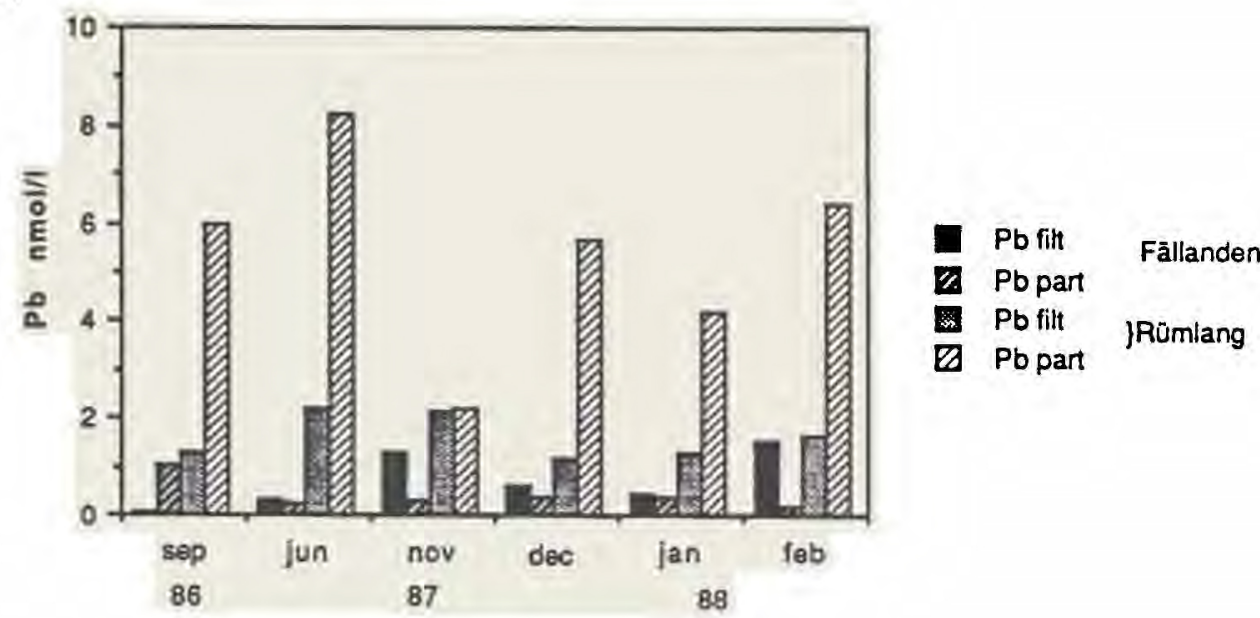

b)

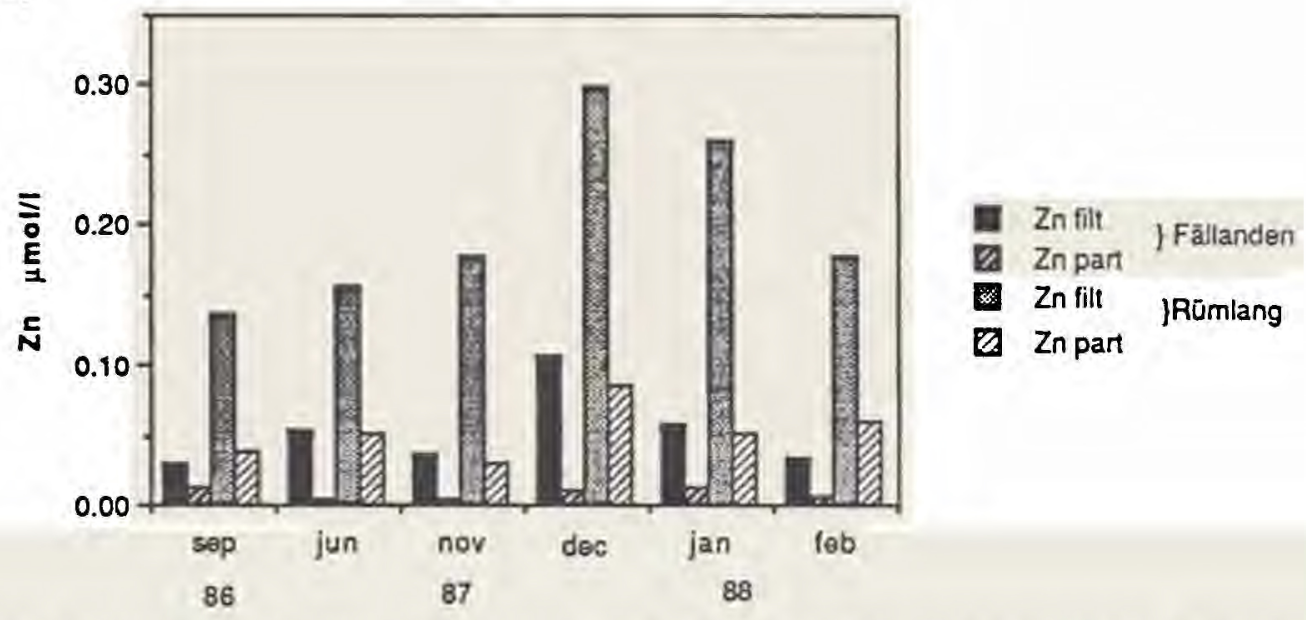

Figure 1. Concentrations measured in water samples from river Glatt at the two sites Fällanden (lake outlet) and Rümlang (after sewage inputs) for 6 examples taken at different dates; filt.: measured in $0.45 \mu \mathrm{m}$ filtered samples; part.: measured in particles collected on the filters. a) concentrations of $\mathrm{Pb}$; b) concentrations of $\mathrm{Zn}$ 
Table 1. Composition of the suspended particles from river Glatt at the two sampling sites Fällanden and Rümlang (collected by centrifugation)

\begin{tabular}{|c|c|c|c|c|c|c|c|c|c|c|c|c|}
\hline & Date & $\begin{array}{l}\text { Sample } \\
\text { no. }\end{array}$ & $\begin{array}{l}\text { Org. C } \\
(\mathrm{mmol} / \mathrm{g})\end{array}$ & $\begin{array}{l}\mathrm{P} \\
(\mathrm{mmol} / \mathrm{g})\end{array}$ & $\mathrm{C} / \mathrm{P}$ & $\begin{array}{l}\mathrm{Ca} \\
(\mathrm{mmol} / \mathrm{g})\end{array}$ & $\begin{array}{l}\mathrm{Fe} \\
(\mathrm{mmol} / \mathrm{g})\end{array}$ & $\begin{array}{l}\mathrm{Mn} \\
(\mathrm{mmol} / \mathrm{g})\end{array}$ & $\begin{array}{l}\mathrm{Zn} \\
(\mu \mathrm{mol} / \mathrm{g})\end{array}$ & $\begin{array}{l}\mathrm{Pb} \\
(\mu \mathrm{mol} / \mathrm{g})\end{array}$ & $\begin{array}{l}\log K_{d} \\
(\mathrm{Zn})\end{array}$ & $\begin{array}{l}\log K_{d} \\
(\mathrm{~Pb})\end{array}$ \\
\hline Fällanden & $\begin{array}{r}\text { 15. Sep. } 86 \\
\text { 3. Jun. } 87 \\
\text { 4. Nov. } 87 \\
\text { 2. Dec. } 87 \\
\text { 6. Jan. } 88 \\
\text { 3. Feb. } 88\end{array}$ & $\begin{array}{l}\text { F1 } \\
\text { F2 } \\
\text { F6 } \\
\text { F5 } \\
\text { F3 } \\
\text { F4 }\end{array}$ & $\begin{array}{r}21.08 \\
9.17 \\
26.00 \\
10.75 \\
11.92 \\
12.42\end{array}$ & $\begin{array}{l}0.135 \\
0.206 \\
0.139 \\
0.123 \\
0.100 \\
0.110\end{array}$ & $\begin{array}{r}156 \\
44 \\
187 \\
88 \\
119 \\
113\end{array}$ & $\begin{array}{l}2.03 \\
3.83 \\
3.23 \\
3.88 \\
3.90 \\
5.08\end{array}$ & $\begin{array}{l}0.041 \\
0.059 \\
0.120 \\
0.172 \\
0.160 \\
0.211\end{array}$ & $\begin{array}{l}0.009 \\
0.008 \\
0.014 \\
0.082 \\
0.160 \\
0.273\end{array}$ & \begin{tabular}{r|}
3.2 \\
3.4 \\
2.4 \\
11.6 \\
12.2 \\
12.7
\end{tabular} & $\begin{array}{l}0.17 \\
0.17 \\
0.13 \\
0.28 \\
0.19 \\
0.48\end{array}$ & $\begin{array}{l}5.02 \\
4.80 \\
4.82 \\
5.04 \\
5.33 \\
5.58\end{array}$ & $\begin{array}{l}6.56 \\
5.78 \\
5.02 \\
5.65 \\
5.65 \\
5.49\end{array}$ \\
\hline Rümlang & $\begin{array}{r}\text { 15. Sep. } 86 \\
\text { 3. Jun. } 87 \\
\text { 4. Nov. } 87 \\
\text { 2. Dec. } 87 \\
\text { 6. Jan. } 88 \\
\text { 3. Feb. } 88\end{array}$ & $\begin{array}{l}\text { R1 } \\
\text { R2 } \\
\text { R6 } \\
\text { R 5 } \\
\text { R 3 } \\
\text { R4 }\end{array}$ & $\begin{array}{r}11.08 \\
8.25 \\
17.42 \\
13.50 \\
14.00 \\
11.08\end{array}$ & $\begin{array}{l}0.198 \\
0.174 \\
0.400 \\
0.274 \\
0.258 \\
0.153\end{array}$ & $\begin{array}{l}56 \\
47 \\
44 \\
49 \\
54 \\
72\end{array}$ & $\begin{array}{l}2.40 \\
3.08 \\
2.05 \\
2.50 \\
2.50 \\
2.58\end{array}$ & $\begin{array}{l}0.333 \\
0.448 \\
0.895 \\
0.842 \\
0.698 \\
0.503\end{array}$ & $\begin{array}{l}0.019 \\
0.058 \\
0.015 \\
0.022 \\
0.033 \\
0.034\end{array}$ & $\begin{array}{r}7.3 \\
8.6 \\
7.2 \\
13.1 \\
11.3 \\
9.0\end{array}$ & $\begin{array}{l}1.17 \\
1.39 \\
0.62 \\
0.77 \\
1.11 \\
1.06\end{array}$ & $\begin{array}{l}4.73 \\
4.74 \\
4.61 \\
4.64 \\
4.64 \\
4.71\end{array}$ & $\begin{array}{l}5.95 \\
5.80 \\
5.47 \\
5.82 \\
5.95 \\
5.81\end{array}$ \\
\hline
\end{tabular}


interesting to note that for lead the differences in dissolved concentrations between the two sites are rather small, while much higher particulate lead concentrations are found in Rümlang than in Fällanden. This is partly due to the higher content of suspended matter. A better illustration of the distribution between water and particulate phase is thus given by distribution coefficients calculated as:

$$
K_{d}=\frac{c_{s}}{c_{w}}
$$

with $c_{s}=$ concentration in particles $(\mathrm{mol} / \mathrm{kg})$ and $c_{w}=$ concentration in water $(\mathrm{mol} / \mathrm{l})$. The obtained $K_{d}$ are given in Table 1 for zinc and lead; while the $K_{d}$ obtained in Fällanden show some variations, those obtained in Rümlang are rather constant over the different sampling times. The relative constancy in Rümlang is expected, since the composition of the water at this location is dominated by the inputs of sewage treatment plants which do not vary much seasonally. A systematic difference appears in the distribution coefficients obtained for $\mathrm{Zn}$, with higher distribution coefficients at the lake outlet; for lead the differences do not seem to be as systematic. The distribution coefficients obtained for lead are about one order of magnitude higher than those obtained for zinc. One limitation of this approach is that it is based on membrane filtered samples, which may include small particles and result in apparently too high concentrations in solution; in this case the determined $K_{d}$ would be lower than they are in reality. In samples (especially from Fällanden, F 1, $\mathrm{F} 2$ and $\mathrm{F} 3$ ) with very low $\mathrm{Pb}$ concentrations in water and in the particles, small contaminations may cause large errors in the calculated $K_{d}$.

The particle composition at the two sampling sites gives some indications of the possible interactions. The suspended matter collected on Fällanden consists mostly of material that originated in the lake itself. The particles show seasonal differences especially in their organic carbon content and in the $\mathrm{C} / \mathrm{P}$ ratio (Table 1), as well as in their manganese and to a lesser extent in their iron content. Aluminum was determined in few samples only; in these $\mathrm{Al} \approx 0.2 \mathrm{mmol} / \mathrm{g}$ was found, which is low and indicates also the predominance of particles formed in the lake. The organic carbon content is especially high during the photosynthetically most productive period of the lake in summer and at the end of the stagnation period. High concentrations of manganese are characteristic for the particles found during the lake overturn, since dissolved $\mathrm{Mn}^{+2}$ is being oxidized and precipitated as manganese oxide at that time. While the lead concentrations in the particles do not show clear seasonal variations, the zinc concentrations are high in the winter samples with high manganese content.

The particles collected in Rümlang originate for a large part from the sewage treatment plants. Only negligible amounts of material from the lake may be carried down to this location. The composition of the suspended material found at this sampling site is thus less subject to seasonal variations. The particles are characterized by a high content of organic carbon, but the $\mathrm{C} / \mathrm{P}$ ratio is much smaller than in the particles from the lake and indicates a different type of material (bacteria, biological debris, $\mathrm{P}$ bound to inorganic particles). The iron concentration is higher than in the particles from the lake and originates probably from sewage, while manganese is 
much lower and varies little. The concentrations of lead and zinc in the particles are in general significantly higher than in Fällanden.

Laboratory experiments with the centrifuged particulate matter are used in order to quantify the binding of metals to the particle surfaces. Results obtained by titrating a metal solution with a suspension of the centrifuged particles are interpreted in terms of binding capacities and conditional stability constants according to equation 8 . The assumption of discrete surface ligands is included therein, the linearity of the functions obtained in this manner indicates the applicability of this approach. Figure 2 shows two representative examples of transformed titration curves: Large linear portions of the functions are obtained, with some deviations at the lower and higher end of the titrations. A distribution of surface sites with different affinities is expected in such natural material, as this has been observed for natural ligands in solution (Buffle, 1987). For some lead titrations steeper slopes at low surface coverage (at the end of titration) were observed (see Fig. 2a) and quantified; they indicate sites with higher affinity and lower concentration. Since the particles used in the experiments contained already a certain concentration of lead, the binding sites with the highest affinity may have been already occupied and thus not be available in the experiments. Even though quantification of these sites with higher binding energy could be quite inexact due to the few data points and very low concentrations of dissolved lead, they were very important in the calculations of distribution coefficients.

The obtained binding capacities and conditional stability constants for the twelve examples of Table 1 are given in Table 2. These results indicate that the particle samples are rather similar with respect to their conditional binding constants for lead and zinc. It appears probable that the same type of binding groups is predominant and of importance in all samples. No systematic difference in the stability constants appears between the particles from the two different sampling locations. But a clear difference between the conditional binding constants for lead and zinc is obtained, with higher conditional binding constants for lead in all examples. This is in agreement with results on the binding of lead and zinc to well defined particle surfaces (Schindler and Stumm, 1987) and with the tendency of these metal ions for binding to oxygen ligands. The reversibility of the adsorption reactions is indicated by the consistency of these results obtained at varying concentrations of surface ligands and variable ratios of metal ions to surface groups.

The binding capacities ( $\equiv L_{T}$, Table 2 ) obtained from the plots as in Fig. 2 according to equation (8) are generally somewhat lower for lead than for zinc. It is reasonable to assume that the same surface sites are available both for lead and zinc. An experiment including both metals in a titration and comparison with theoretical calculation of the titration curve using binding constants and adsorption capacities confirmed the validity of this approach. We have to add the concentration of sites that were already occupied by the metal ions in the river. Therefore $\mathrm{Zn}$ (resp. Pb) that desorbed from the particles at $\mathrm{pH} 4$ was added to the determined adsorption capacity of $\mathrm{Pb}$ (resp. $\mathrm{Zn}$ ). ( $\mathrm{pH}$ 4-desorbed $\mathrm{Pb}$ and $\mathrm{Zn}$ was already included in the adsorption capacities of the concerned metals). We then obtain the total numbers of sites

$$
\left\{\equiv L_{T}\right\}=\left\{\equiv L_{T}^{\mathrm{Pb}}\right\}+\left\{\mathrm{Zn}_{\text {desorbed }}\right\} \quad \text { and } \quad\left\{\equiv L_{T}\right\}=\left\{\equiv L_{T}^{\mathrm{Zn}}\right\}+\left\{\mathrm{Pb}_{\text {desorbed }}\right\}
$$

represented in Table 2, which result in good agreement for lead and zinc. 

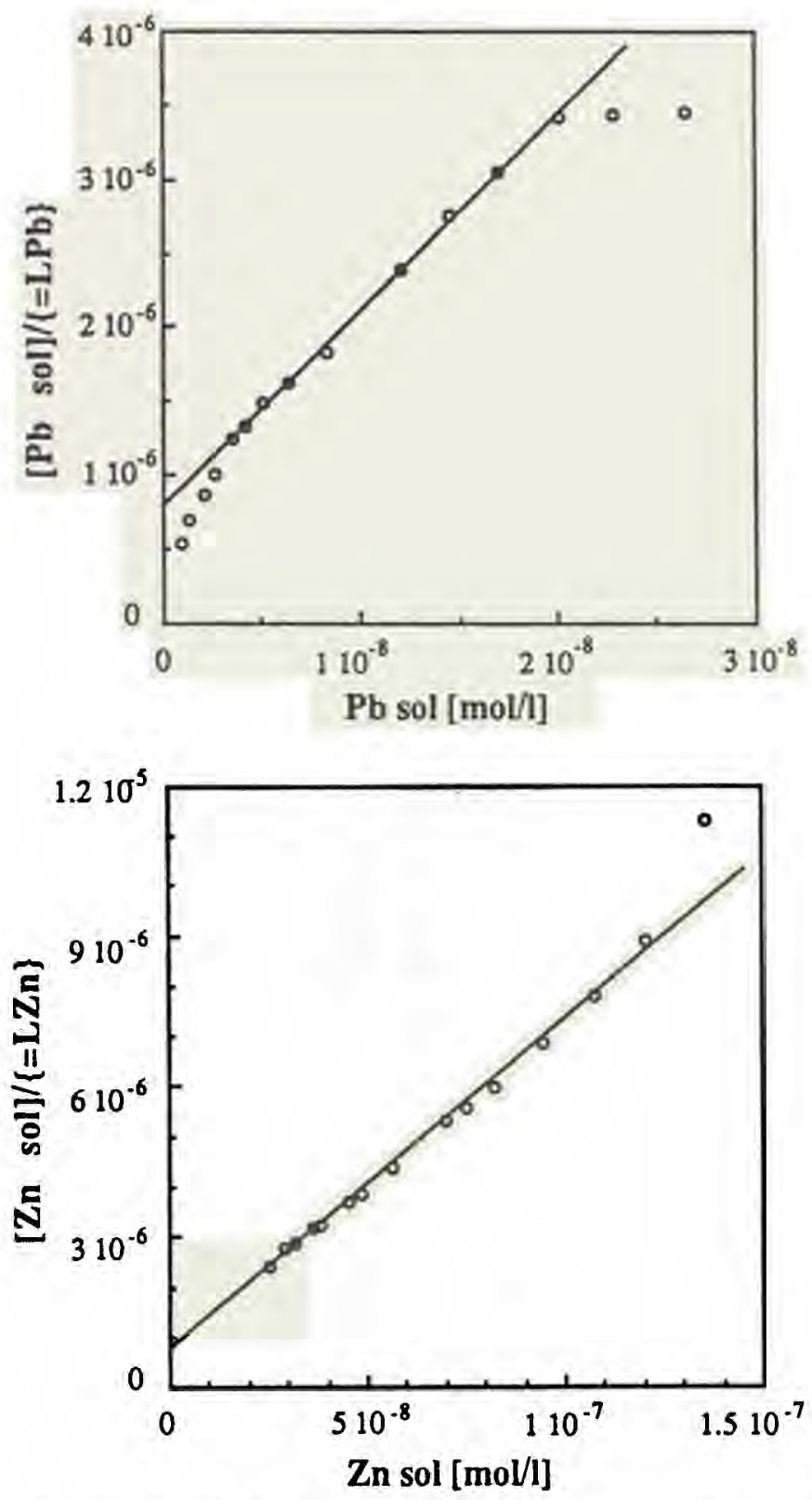

Figure 2. Representative examples of linearized titration curves of metal ions with natural particles plotted according to eq. (8). Increments of a suspension of the particles $F 3(2 \mathrm{~g} / \mathrm{l})$ were added to a solution of $1.53 \cdot 10^{-7} \mathrm{M} \mathrm{Zn}$ resp. $4.83 \cdot 10^{-8} \mathrm{M} \mathrm{Pb}$ (ionic medium: $10^{-2} \mathrm{M} \mathrm{KNO}_{3} / 10^{-3} \mathrm{M} \mathrm{HCO}_{3}^{-}$, purged with $\left.\mathrm{N}_{2} / 0.06 \% \mathrm{CO}_{2}, \mathrm{pH}=8\right)$. In the range 3-30 $(\mathrm{Pb})$ and 3-60 $(\mathrm{Zn}) \mathrm{mg}$ particles per liter, the experimental points fit a straight line of which the slope and intercept give values for the binding capacity $\equiv L_{T}$ and $\log K$. Deviations from this line are observed at low $M e /$ surface ratio (low end of titration curve) where sites with higher affinity are effective, and at high $\mathrm{Me}$ /surface ratio, where saturation of the surface occurs

Differences in binding capacities of different samples are significant, but again not systematic with respect to material from the different sampling locations. We may attempt to relate the adsorption capacities calculated from the experiments to the composition of the solid phase. Some tendencies can be derived by comparing the adsorption capacities with the particle composition. The number of experimentally 
Table 2. Experimentally evaluated binding capacities $\left(\equiv L_{T}\right.$ ) and conditional binding constants ( $\log K)$ of particles from river Glatt. The total numbers of surface sites (tot. sites) were calculated as the sum of the measured binding capacity of $\mathrm{Pb}$ (respectively $\mathrm{Zn}$ ) and of $\mathrm{Zn}$ (respectively $\mathrm{Pb}$ ) already present in the particles (desorbed at $\mathrm{pH} 4$ ). The average total sites are mean values of the results obtained from the experiments with $\mathrm{Pb}$ and $\mathrm{Zn}$. The distribution coefficients $\left(K_{d}^{\text {cale. }}\right)$ were calculated with the MICROQL-speciation program using the total metal concentrations, $\mathrm{pH}$, alkalinity and particle concentrations from the field data and the corresponding experimental average total sites and $\log K$. (E -3 means $\left.10^{-3}\right)$

\begin{tabular}{|c|c|c|c|c|c|c|c|}
\hline Date & $\mathrm{Pb}$ & $\begin{array}{l}\equiv L_{\mathrm{J}} \\
(\mathrm{M} / \mathrm{kg})\end{array}$ & $\log K$ & $\begin{array}{l}\text { Tot. sites } \\
(\mathrm{M} / \mathrm{kg})\end{array}$ & $\begin{array}{l}\text { Average } \\
\text { total sites } \\
(\mathrm{M} / \mathrm{kg})\end{array}$ & $K_{i}^{\text {cale. }}$ & $K_{d}^{\text {field }}$ \\
\hline $\begin{array}{r}\text { 15. Sep. } 86 \\
\text { 3. Jun. } 87 \\
\text { 4. Nov. } 87 \\
\text { 2. Dec. } 87 \\
\text { 6. Jan. } 88 \\
\text { 3. Feb. } 88\end{array}$ & $\begin{array}{l}\text { F1 } \\
\text { F2 } \\
\text { F6 } \\
\text { F5 } \\
\text { F3 } \\
\text { F4 }\end{array}$ & & $\begin{array}{l}9.31 \\
9.05 \\
9.42 \\
9.31 \\
9.36 \\
9.70\end{array}$ & $\begin{array}{l}3.80 \mathrm{E}-3 \\
5.15 \mathrm{E}-3 \\
8.62 \mathrm{E}-3 \\
1.24 \mathrm{E}-2 \\
1.69 \mathrm{E}-2 \\
1.31 \mathrm{E}-2\end{array}$ & $\begin{array}{l}9.35 \mathrm{E}-3 \\
5.32 \mathrm{E}-3 \\
8.57 \mathrm{E}-3 \\
1.07 \mathrm{E}-2 \\
1.65 \mathrm{E}-2 \\
1.17 \mathrm{E}-2\end{array}$ & $\begin{array}{l}5.68 E+5 \\
2.42 E+4 \\
1.59 E+5 \\
5.48 E+4 \\
3.38 E+5 \\
2.98 E+5\end{array}$ & $\begin{array}{l}3.60 E+6 \\
6.00 E+5 \\
1.04 E+5 \\
4.50 E+5 \\
4.40 E+5 \\
3.13 E+5\end{array}$ \\
\hline $\begin{array}{r}\text { 15. Sep. } 86 \\
\text { 3. Jun. } 87 \\
\text { 4. Nov. } 87 \\
\text { 2. Dec. } 87 \\
\text { 6. Jan. } 88 \\
\text { 3. Feb. } 88\end{array}$ & $\begin{array}{l}\text { R1 } \\
\text { R2 } \\
\text { R6 } \\
\text { R5 } \\
\text { R3 } \\
\text { R4 }\end{array}$ & & $\begin{array}{l}9.68 \\
9.33 \\
9.57 \\
9.36 \\
9.60 \\
9.60\end{array}$ & $\begin{array}{l}8.21 \mathrm{E}-3 \\
8.77 \mathrm{E}-3 \\
1.32 \mathrm{E}-2 \\
1.65 \mathrm{E}-2 \\
1.47 \mathrm{E}-2 \\
9.90 \mathrm{E}-3\end{array}$ & $\begin{array}{l}8.29 E-3 \\
8.86 E-3 \\
1.33 E-2 \\
1.55 E-2 \\
1.41 E-2 \\
1.13 E-2\end{array}$ & $\begin{array}{l}2.66 E+5 \\
4.56 E+4 \\
1.84 E+5 \\
3.27 E+4 \\
6.01 E+4 \\
1.49 E+5\end{array}$ & $\begin{array}{l}9.00 E+5 \\
6.28 E+5 \\
2.93 E+5 \\
6.67 E+5 \\
8.85 E+5 \\
6.47 E+5\end{array}$ \\
\hline & $\mathrm{Zn}$ & & & & & & \\
\hline $\begin{array}{r}\text { 15. Sep. } 86 \\
\text { 3. Jun. } 87 \\
\text { 4. Nov. } 87 \\
\text { 2. Dec. } 87 \\
\text { 6. Jan. } 88 \\
\text { 3. Feb. } 88\end{array}$ & $\begin{array}{l}\text { F1 } \\
\text { F2 } \\
\text { F6 } \\
\text { F5 } \\
\text { F3 } \\
\text { F4 }\end{array}$ & $\begin{array}{l}9.28 \mathrm{E}-3 \\
5.38 \mathrm{E}-3 \\
8.41 \mathrm{E}-3 \\
8.91 \mathrm{E}-3 \\
1.60 \mathrm{E}-2 \\
1.03 \mathrm{E}-2\end{array}$ & $\begin{array}{l}7.82 \\
8.21 \\
8.18 \\
8.31 \\
8.01 \\
8.56\end{array}$ & $\begin{array}{l}9.35 E-3 \\
5.50 E-3 \\
8.53 E-3 \\
9.07 E-3 \\
1.60 E-2 \\
1.03 E-2\end{array}$ & & $\begin{array}{l}2.09 E+5 \\
7.31 E+4 \\
1.72 E+5 \\
9.13 E+4 \\
2.38 E+5 \\
3.49 E+5\end{array}$ & $\begin{array}{l}1.05 E+5 \\
6.29 E+4 \\
6.67 E+4 \\
1.09 E+5 \\
2.16 E+5 \\
3.77 E+5\end{array}$ \\
\hline $\begin{array}{r}\text { 15. Sep. } 86 \\
\text { 3. Jun. } 87 \\
\text { 4. Nov. } 87 \\
\text { 2. Dec. } 87 \\
\text { 6. Jan. } 88 \\
\text { 3. Feb. } 88\end{array}$ & $\begin{array}{l}\text { R 1 } \\
\text { R2 } \\
\text { R6 } \\
\text { R 5 } \\
\text { R3 } \\
\text { R4 }\end{array}$ & $\begin{array}{l}7.82 \mathrm{E}-3 \\
8.25 \mathrm{E}-3 \\
1.31 \mathrm{E}-2 \\
1.43 \mathrm{E}-2 \\
1.31 \mathrm{E}-2 \\
1.22 \mathrm{E}-2\end{array}$ & $\begin{array}{l}8.20 \\
8.07 \\
8.06 \\
8.39 \\
8.32 \\
7.93\end{array}$ & $\begin{array}{l}8.36 E-3 \\
8.94 E-3 \\
1.34 E-2 \\
1.45 E-2 \\
1.35 E-2 \\
1.26 E-2\end{array}$ & & $\begin{array}{l}5.59 E+4 \\
4.53 E+4 \\
7.73 E+4 \\
5.98 E+4 \\
5.22 E+4 \\
5.06 E+4\end{array}$ & $\begin{array}{l}5.39 E+4 \\
5.49 E+4 \\
4.05 E+4 \\
4.39 E+4 \\
4.35 E+4 \\
5.09 E+4\end{array}$ \\
\hline
\end{tabular}

available sites increases with increasing content of organic carbon in the samples from both locations. Two samples from Fällanden (F1 and F6) with very high organic $\mathrm{C}$ are here exceptions due probably to their very low $\mathrm{Mn}$ - and $\mathrm{Fe}$-content compared with the other samples which may also play a significant role in adsorption. In comparison with the Fe content of the particles, the number of surface sites in the Rümlang samples is correlated with increasing $\mathrm{Fe}$, while the samples from Fällanden all have low $\mathrm{Fe}$ and other parameters seem to dominate. Three samples from Fällanden have $\mathrm{Mn}>0.05 \mathrm{mmol} / \mathrm{g}$, while all other samples are rather low in $\mathrm{Mn}$. These three samples have increased binding capacities in comparison to the other samples from Fällanden. No clear dependence of the binding capacity on $\mathrm{Ca}$ or $\mathrm{P}$ is found. From these data we assume that a large fraction of the binding groups is 
related to the organic material and that high iron oxide or manganese oxide content provides additional binding groups.

\section{Discussion}

The combination of field measurements and laboratory experiments allows to examine the following questions: Can the distribution of metal ions between particulate and dissolved phases be explained in terms of simple interactions with surfaces on the basis of the obtained surface parameters? Are the differences in distribution (as reflected by the distribution coefficients) explained by different binding properties of the particles?

For this purpose the distribution coefficients are derived from speciation calculations which include the interactions with suspended particles by using the binding parameters given in Table 2 and the concentrations of metal ions, of suspended matter, $\mathrm{pH}$ and alkalinity measured in the Glatt river. The competition of $\mathrm{Zn}$ and $\mathrm{Pb}$ for the surface sites is included in this calculation. The $\mathrm{pH}$ dependence cannot be assessed, since the experiments were carried out at constant $\mathrm{pH}(\mathrm{pH}=8.0)$; this $\mathrm{pH}$ is representative for the river $(\mathrm{pH}=7.7-8.2)$. Different assumptions have to be made on the composition of the solution: in the simplest case only the complexation with hydroxide and carbonate is considered (assumed for the results given in Fig. 3); for more elaborate calculations, complexation by NTA, EDTA, natural organic ligands and competition effects of cations can be included.

Figure 3 compares the calculated $K_{d}$ values with those measured in the river for zinc and lead. Numeric values are given in Table 2. Calculated $K_{d}$ for $\mathrm{Zn}$ are very consistent with the field data both for the results in Rümlang and in Fällanden, the



Figure 3. Comparison of distribution coefficients measured in the river Glatt with the calculated values using the experimentally obtained binding constants and adsorption capacities and concentrations, $\mathrm{pH}$ etc. corresponding to the conditions determined in the river 
competition with $\mathrm{Pb}$ for the surface sites has little influence on the resulting $K_{d}$ because of the smaller concentrations of $\mathrm{Pb}$. The concentrations of surface sites as calculated from the concentrations of suspended matter in the river and experimentally determined binding capacities for the field conditions are generally smaller than the zinc concentrations, so that the concentration of adsorbed zinc is limited by the number of available sites. Therefore the lower $K_{d}$ observed at the Rümlang site compared to Fällanden could be explained by an insufficient capacity of the suspended matter for adsorption of $\mathrm{Zn}$. The cases in Fällanden with high $K_{d}$ are confirmed by the calculations; both high adsorption capacities and high binding constants contribute to high distribution coefficients in the cases $F 3$ and $F 4$, where the particulate matter is characterized by a high content of manganese oxide.

The calculated overall speciation of zinc is still dominated by the dissolved species (Fig. 4), especially by the free $\mathrm{Zn}^{+2}$ ion. In order to check the effect of EDTA and NTA, the competition of $\mathrm{Cu}$ and $\mathrm{Ca}$ for these ligands has to be included. Calculations with the typical concentrations of EDTA and NTA for Rümlang (Giger et al., 1987), namely EDTA $=7.2 \cdot 10^{-8} \mathrm{M}, \mathrm{NTA}=3.8 \cdot 10^{-8} \mathrm{M}$, result in only slightly decreased $K_{d}$ for $\mathrm{Zn}$ (less than $5 \%$ ).

The calculated concentrations of surface sites are in all cases higher than the total lead concentrations (by a factor of at least 3 and up to 10). In spite of the higher binding constants for lead there is a strong competition by the high concentration of zinc, and the distribution coefficients react very sensitively to changes in the solution composition. Taking only the low-energy binding sites of lead into account for the calculation, the resulting $K_{d}$ 's for lead are much lower than the field values by about one order of magnitude (except for the samples F 3, F 4, F 6 and R6). This indicates that the sites with higher binding constants we found for the samples F 3, F 5, R1, R 2, $\mathrm{R} 3$ and R 5 might be relevant. The calculations with these surface ligands enclosed gave the good correlation in Fig. 3. F 1 and F 2 are exceptions. We suspect that small contaminations could alter the very small lead concentration of these particular samples and thus change the distribution coefficient in a wide range. The presence of a small number of strong binding sites is expected to affect also $\mathrm{Zn}$, but due to the much higher relative concentration of dissolved $\mathrm{Zn}$ this effect is not apparent in the calculated $K_{d}$.

The values obtained here for conditional stability constants with natural particles may be compared, on one hand, with the stability constants for defined surfaces and on the other hand with results obtained by others for natural particles. The stability constants for $\mathrm{Pb}$ may be compared with our own data for the binding of $\mathrm{Pb}$ to goethite (Müller, 1989). Since both $1: 1\left(\equiv \mathrm{FeOOPb}^{+}\right)$and $1: 2\left((\equiv \mathrm{FeOO})_{2} \mathrm{~Pb}\right)$ complexes are assumed to exist on the goethite surface, the quotients

$$
Q=\frac{\left\{\mathrm{Pb}_{\mathrm{ads}}\right\}}{\left[\mathrm{Pb}^{+2}\right]}
$$

have to be evaluated from the constants and compared. For goethite with $5.6 \cdot 10^{-2} \mathrm{~mol} / \mathrm{kg}$ binding capacity, $\log Q=7.35$ is obtained. Using an average value of the surface constants for the natural particles we find $\log Q=7.23$. The natural particles appear to bind $\mathrm{Pb}$ with a similar affinity as goethite surface groups. Similar 
Trace metal adsorption on natural particles
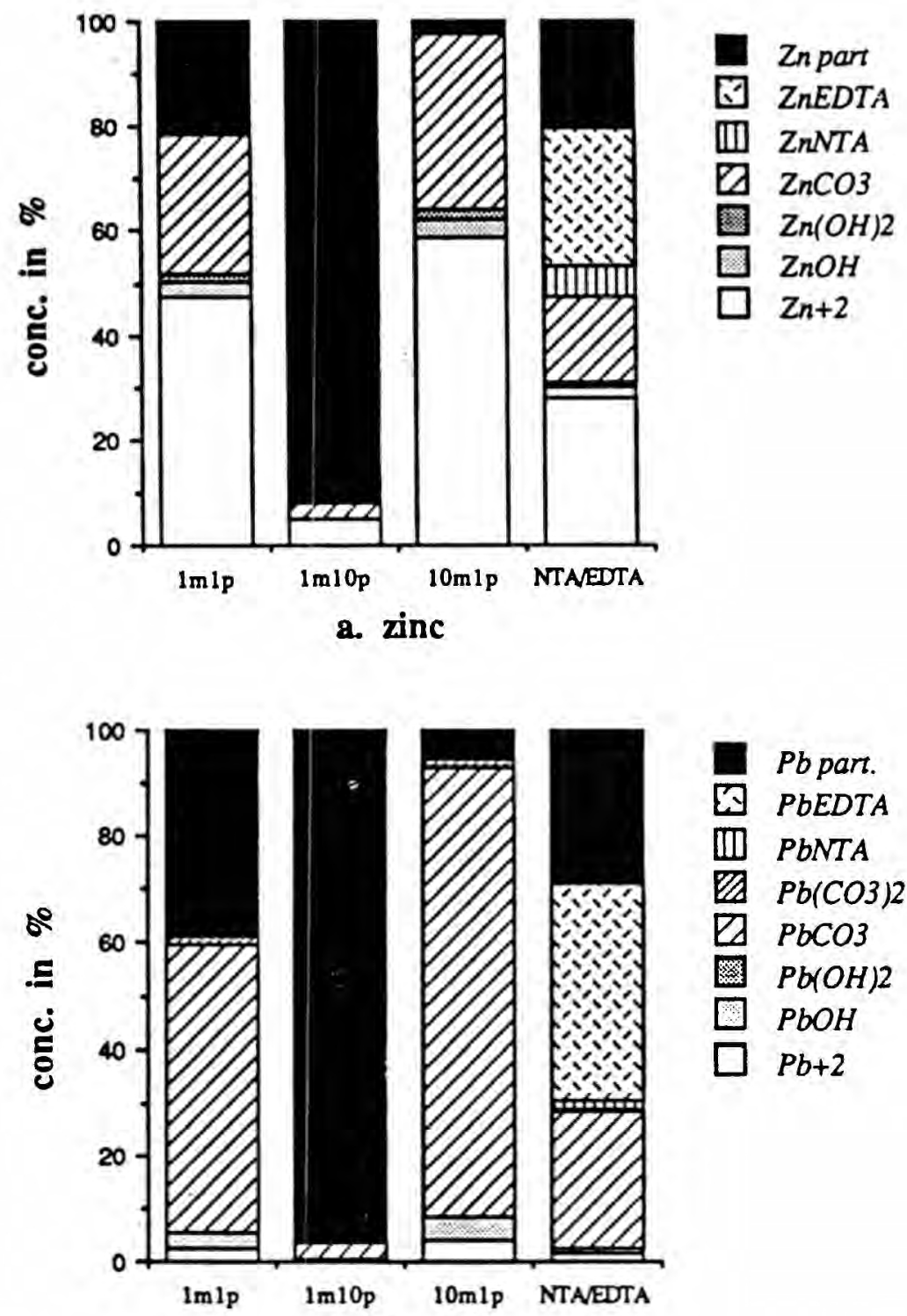

b. lead

Figure 4. Example of the calculated speciation of $\mathrm{Zn}$ and $\mathrm{Pb}$ ( $\%$ of total concentration in water), including in solution the hydroxo and carbonato complexes and the experimental conditional binding constants and capacities for the suspended particles of the sample R 6: a) Zinc speciations: $1 \mathrm{~m} 1 \mathrm{p}$ means $\left[\mathrm{Zn}_{T}\right]=1.94 \cdot 10^{-7} \mathrm{M}$ and suspended particles $=3.5 \mathrm{mg} / 1$ which corresponds to $\left[\equiv L_{T}\right]=4.7 \cdot 10^{-8} \mathrm{M}$. These conditions correspond to the actually measured values for the sample R6. At $1 \mathrm{~m} \mathrm{10p}$ the concentration of the particles is ten times larger than before at the same metal concentration. $10 \mathrm{~m} 1 \mathrm{p}$ means normal particle concentration and ten times elevated metal concentration. NTA/EDTA: NTA $=3.77 \cdot 10^{-8} \mathrm{M}, \quad$ EDTA $=7.2 \cdot 10^{-8} \mathrm{M}, \quad \mathrm{Ca}=1.72 \mathrm{mM}$, $\mathrm{Cu}=2.52 \cdot 10^{-8} \mathrm{M}$, all other concentrations like $1 \mathrm{~m} 1 \mathrm{p} ;$ b) Speciation for lead with $\left[\mathrm{Pb}_{T}\right]=1.11 \cdot 10^{-8} \mathrm{M}$. Modifications were the same as mentioned for zinc 
binding affinity could however also be obtained by other surfaces, e.g. organic functional groups. The comparison for the binding constants does not allow to identify clearly the type of surface groups.

Our data for natural particles may be compared with those of Balistrieri and Murray $(1983,1984)$, who worked with marine sediments. They define a quotient

$$
K_{s w} \frac{\{M e\}_{\text {ads }}}{\left[M e_{\text {sol }}\right] \cdot N_{s}^{-1}}
$$

with $N_{s}=$ total number of available binding sites. They obtain $\log K_{s w}=6.08$ for $\mathrm{Pb}$ and $\log K_{s w}=4.7$ for $\mathrm{Zn}$ for the ionic composition of seawater, or after multiplying by $N_{s}: \log K_{s w}^{\prime}=6.54$ for $\mathrm{Pb}$ and $\log K_{s w}^{\prime}=5.13$ for $\mathrm{Zn} ; K_{s w}^{\prime}$ is equivalent to our $K_{d}$. Our values for $\mathrm{Pb}$ are $\log K_{d}=5.0-6.2$, and for $\mathrm{Zn} \log K_{d}=4.6-5.5$; they are thus in the same order of magnitude as the data of Balistrieri and Murray (1984) for $\mathrm{Zn}$ and somewhat lower for $\mathrm{Pb}$.

Equilibration of metal ions with the particle surfaces means that the fraction of total metal concentration bound to particles depends on the concentration of suspended particles. An increase of the concentration of particles which is often observed in the river under conditions of high water discharge (Gujer et al., 1982), would usually lead to a lower ratio of total metal concentrations to surface groups. This means that in the case of high particle concentrations the surface groups may be in excess both of $\mathrm{Zn}$ and $\mathrm{Pb}$, so that the surface equilibria result in increasing the fraction of $\mathrm{Zn}$ and $\mathrm{Pb}$ bound to the particles. An example of the calculated speciation for the actual concentration of particles and for a tenfold increase is given in Fig. 4 . $(1 \mathrm{~m} 10 \mathrm{p})$. A tenfold increase of metal concentrations at unchanged particle concentration (Fig. $4,10 \mathrm{~m} 1 \mathrm{p}$ ) results in a very high percentage of dissolved metal since the adsorption capacity of the surfaces is then saturated. The percentages of the free aqueous ion are in this case higher than at normal levels of metal concentration ( $1 \mathrm{~m} 1 \mathrm{p}$ ); since the concentration of free aqueous ion has been in many cases shown to be the determining factor for toxicity effects, this means that toxic effects may increase in overproportion to the total concentrations. The inclusion of NTA $=3.77 \cdot 10^{-8} \mathrm{M}$ and EDTA $=7.2 \cdot 10^{-8} \mathrm{M}$ in the calculations leads to a decrease of metal ions bound to particles and also to a decrease of the free aqueous metal ions; the EDTA species are both for $\mathrm{Zn}$ and $\mathrm{Pb}$ more abundant than the NTA species.

\section{Conclusions}

Adsorption experiments with natural particle surfaces show that a surface chemical approach can be used for the natural suspended matter. Conditional adsorption equilibria parameters can be derived from such experiments by a simplified approach and give consistent results for suspended matter collected from the same system at different times. From the overall composition of the particles and the experimentally obtained binding capacities, organic material, iron and manganese oxides appear to be the most important phases for adsorption. 
The surfaces of natural suspenced matter in river water regulate the concentration of metal ions in solution. A competition of the different metal ions for the available surface sites is expected. Comparison of the distribution of $\mathrm{Zn}$ and $\mathrm{Pb}$ obtained under field conditions with the experimental results indicate that the distribution of these metals is in agreement with the experimental surface parameters. A second surface ligand with different concentrations and binding energies could be determined for lead in some samples and appeared to be relevant for the calculation of the distribution coefficients.

The surface chemical approach to the interactions of metal ions with natural particle surfaces gives a chemical basis for the understanding of distribution coefficients and allows to predict changes in dissolved and particulate concentrations as a function of different factors.

\section{ACKNOWLEDGEMENT}

We thank Werner Stumm for introducing us to surface chemistry and for encouraging us in this work. Above all we are very grateful for the freedom, generosity and confidence we enjoyed as his students and coworkers. We thank David Kistler and Ursula Lindauer for analytical work and for collegiality.

\section{REFERENCES}

Buffle, J., and R.S. Altmann, 1987. Interpretation of metal complexation by heterogeneous complexants. In: W. Stumm (ed.), Aquatic Surface Chemistry, Wiley, New York: pp. 351-383.

Balistrieri, L., P. G. Brewer and J. W. Murray, 1981. Scavenging residence times of trace metals and surface chemistry of sinking particles in the deep ocean. Deep-sea Res. 28 A:101-121.

Balistrieri, L., and J. W. Murray, 1983. Metal-solid interaction in the marine environment: estimating apparent equilibrium binding constants. Geochim. Cosmochim. Acta 47:1091-1098.

Balistrieri, L., and J.W. Murray, 1984. Marine scavenging: trace metal adsorption by interfacial sediment from MANOP site H. Geochim. Cosmochim. Acta 48:921-929.

Giger, W., 1987. Jahresbericht EAWAG, Dübendorf.

Gujer, W., V. Krejci, R. Schwarzenbach and J. Zobrist, 1982. Von der Kanalisation ins Grundwasser - Charakterisierung eines Regenereignisses im Glattal. Gas, Wasser, Abwasser 999:298-311.

Jacobs, L. A., H. R. von Gunten, R. Keil and M. Kuslys, 1988. Geochemical changes along a rivergroundwater infiltration flow path: Glattfelden, Switzerland. Geochim. Cosmochim. Acta 52:2693-2706.

Johnson, C. A., 1986. The regulation of trace element concentrations in river and estuarine waters contaminated with acid mine drainage: The adsorption of $\mathrm{Cu}$ and $\mathrm{Zn}$ on amorphous $\mathrm{Fe}$ oxyhydroxides. Geochim. Cosmochim. Acta 50:2433-2438.

Lion, L.W., R. S. Altmann and J. O. Leckie, 1982. Trace-metal adsorption characteristics of estuarine particulate matter: evaluation of contributions of $\mathrm{Fe} / \mathrm{Mn}$ oxide and organic surface coatings. Environ. Sci. Technol. 16:660-666.

Morel, F. M. M., and R. J. M. Hudson, 1985. The geobiological cycle of trace elements in aquatic systems: Redfield revisited. In: W. Stumm (ed.), Chemical processes on lakes. New York: Wiley, pp. 251-281.

Mouvet, C., and A. C. M. Bourg, 1983. Speciation (including adsorbed species) of copper, lead, nickel and zinc in the Meuse river. Water Res. 17:641-649.

Müller, B., 1989. Über die Adsorption von Metallionen an Oberflächen aquatischer Partikel. Ph. D. Thesis No. 8988. Swiss Federal Institute of Technology, ETH Zürich.

Müller, B., and L. Sigg, 1990. (to be published).

Ruzic, I., 1982. Theoretical aspects of the direct titration of natural waters and its information yield for trace metal speciation. Anal. Chim. Acta 140:99-113. 
Ruzic, I., 1987. Correspondence: Comment on "Metal-humate interactions. 1 and 2." Environ. Sci. Technol. $21: 1132-1135$.

Schindler, P., 1984. Surface Complexation. In: H. Sigel (ed.), Metal ions in biological systems, vol. 18, New York: M. Dekker.

Schindler, P., and Stumm, W., 1987. The surface chemistry of oxides, hydroxides and oxide minerals. In: W. Stumm (ed.), Aquatic Surface Chemistry, New York: Wiley, pp. 83-110.

Sigg, L., 1987. Surface chemical aspects of the distribution and fate of metal ions in lakes. In: W. Stumm (ed.), Aquatic Surface Chemistry, New York: Wiley, pp. 319-349.

Sigg, L., M. Sturm and D. Kistler, 1987. Vertical transport of heavy metals by settling particles in Lake Zurich. Limnol. Oceanogr. 32:112-130.

Sigg, L., D. Kistler and U. Lindauer, 1990. Distribution of trace metals between particulate phase and solution in a small river system (in preparation).

Smith, R. M., and Martell, A. E., 1976. Critical stability constants. Plenum Press, New York.

Sposito, G., 1984. The surface chemistry of soils. Oxford University Press, New York.

Tessier, A., F. Rapin and R. Carignan, 1985. Trace metals in oxic lake sediments: possible adsorption onto iron oxyhydroxides. Geochim. Cosmochim. Acta 49, 183-194.

Van den Berg, C. M. G., and J. R. Kramer, 1979. Determination of complexing capacities of ligands in natural waters and conditional stability constants of the copper complexes by means of manganese dioxide. Anal. Chim. Acta 106:113-120.

Westall, J. C., 1979. "MICROQL, a chemical equilibrium program in BASIC". Internal report, EAWAG, Dübendorf.

Westall, J. C., 1987. Adsorption mechanisms in aquatic surface chemistry. In: W. Stumm (ed.), Aquatic Surface Chemistry, New York: Wiley, pp. 3-32.

Whitfield, M., and Turner D. R., 1987. The role of particles in regulating the composition of seawater. In: W. Stumm (ed.), Aquatic Surface Chemistry, New York: Wiley, pp. 457-493.

Received 6 October 1989. 